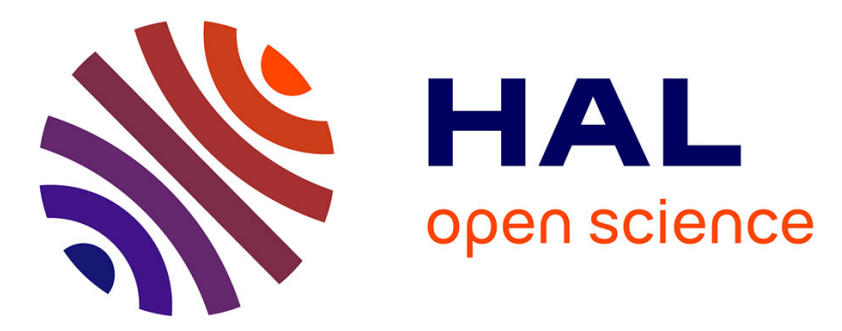

\title{
Ozone monitoring in the troposphere and lower stratosphere: Evaluation and operation of a ground-based lidar station
}

\author{
Jacques Pelon, Gérard Mégie
}

\section{To cite this version:}

Jacques Pelon, Gérard Mégie. Ozone monitoring in the troposphere and lower stratosphere: Evaluation and operation of a ground-based lidar station. Journal of Geophysical Research. Oceans, 1982, 87 (C7), pp.4947-4955. 10.1029/JC087iC07p04947 . insu-01263555

HAL Id: insu-01263555

https://hal-insu.archives-ouvertes.fr/insu-01263555

Submitted on 12 Mar 2021

HAL is a multi-disciplinary open access archive for the deposit and dissemination of scientific research documents, whether they are published or not. The documents may come from teaching and research institutions in France or abroad, or from public or private research centers.
L'archive ouverte pluridisciplinaire $\mathbf{H A L}$, est destinée au dépôt et à la diffusion de documents scientifiques de niveau recherche, publiés ou non, émanant des établissements d'enseignement et de recherche français ou étrangers, des laboratoires publics ou privés. 


\title{
Ozone Monitoring in the Troposphere and Lower Stratosphere: Evaluation and Operation of a Ground-Based Lidar Station
}

\author{
Jacques Pelon and Gérard Mégie \\ Service d'Aéronomie du CNRS, 91370 Verrières-le-Buisson, France
}

\begin{abstract}
Ozone monitoring in the troposphere and lower stratosphere has been performed on an operational basis by using a ground-based lidar station set up in 1980 at the Haute Provence Observatory (France). A description of the experimental system is given with a special emphasis on the technical achievements that take into account the optimization criteria of the differential absorption laser technique used in the measurements. The results obtained during several experiments in 1980-1981 are discussed in terms of ozone variability in the troposphere and lower stratosphere, ozone exchanges between these two altitude regions, and tropospheric ozone budget.
\end{abstract}

\section{INTRODUCTION}

Continuous monitoring of the ozone vertical profile in the troposphere and stratosphere is a basic requirement in present day atmospheric physics, as the possible depletion of the ozone layer by catalytic chemical cycles involving trace constituents of anthropogenic origin could greatly modify the earth's environment and climate. The measurement of the total ozone column content by means of the ground-based UV spectrometer network or by satelliteborne systems remains the fundamental basis for global observations and trend analysis [NASA, 1979a]. However, the very large variability of the ozone number density as observed in the troposphere and lower stratosphere [Dütsch, 1979] and its interpretation in terms of horizontal and vertical transport requires high spatial resolution measurements. These are of particular interest for the understanding and quantitative evaluation of the net ozone budget in terms of sources and sinks of atmospheric ozone and stratospheretroposphere mass exchanges. The recent development of powerful tunable lasers has opened a new experimental field for spectroscopic studies of atmospheric trace constituents. As part of it, the differential absorption laser technique (DIAL) has already been used for ground-based measurements of minor constituents in the boundary layer [Cahen et al., 1981a; Frederiksson et al., 1979; Murray et al., 1977]. In a similar way, with the advent of the NASA Space Shuttle transportation system as a platform, global measurements of atmospheric species, using a pulsed lidar system, become feasible and have already been evaluated [Remsberg and Gordley, 1978; Megie and Menzies, 1980].

Vertical concentration profiles of atmospheric ozone have also been recorded by using UV and IR lidar systems; however, these measurements have been restricted either to the boundary layer [e.g., Asai et al., 1979; Bufton et al., 1979; Browell et al., 1981] or to the stratosphere [Megie et al., 1977; Uchino et al., 1980]. The purpose of this paper is to describe the evaluation and realization of a ground-based UV lidar system for continuous monitoring of the ozone number density profile from the ground up to the $25-30 \mathrm{~km}$ range. The operational aspects of the system and the results of various experiments performed at the Haute Provence

Copyright 1982 by the American Geophysical Union.

Paper number $2 \mathrm{C} 0038$.

0148-0227/82/002C-0038\$05.00
Observatory in the south of France $\left(44^{\circ} \mathrm{N}, 6^{\circ} \mathrm{E}\right)$ will be discussed.

\section{MeTHODOLOGY}

The basic principles of the differential absorption laser technique (DIAL) have been described by various authors [Schotland, 1964; Byer and Garbuny, 1973]. Its application to ozone measurements for both UV and IR systems has also been analyzed by Megie and Menzies [1980]. in the case of a spaceborne experiment. A detailed development of the DIAL technique will thus not be presented here, and only the points of interest for a ground-based system will be emphasized starting from the errors derivation presented in the appendix: the ozone number density in the altitude range $R, R+\Delta R$ (see appendix for notations) is directly derived by processing laser signals corresponding to successive altitude ranges and to two different wavelengths $\lambda_{1}$ and $\lambda_{2}$ in the UV absorption bands of ozone.

\section{Error Analysis}

The general expression of the relative uncertainty $\varepsilon$ on the ozone number density as derived in the appendix depends on a large number of interrelated parameters and can be expressed as the sum of two terms: (1) the statistical error $\varepsilon_{1}$ due to the signal and background noise fluctuations and (2) a systematic error $\varepsilon_{2}$ due to the approximations made when neglecting the wavelength dependence of the scattering and absorbing properties of aerosol layers and tenous cirrus clouds.

A minimum value of $\varepsilon$ can be obtained for a given range by an appropriate choice of the laser emission wavelengths $\lambda_{1}$ and $\lambda_{2}$. In the general case, this optimization of the DIAL measurement requires a numerical computation to include the experimental parameters of the lidar system and the atmospheric parameters related to molecular and aerosols scattering and ozone absorption. The description of such computations are beyond the scope of this paper; however, a simple analysis can be made by considering separately the lower $(0-2 \mathrm{~km})$ and higher altitude ranges, as the relative contribution of the molecular and aerosol extinctions will be different in these two cases.

Boundary layer and lower tropospheric measurements. Below $2 \mathrm{~km}, \varepsilon_{2}$ becomes the most important error term as the molecular and aerosol extinctions are large and as the backscattered signal is intense enough so that the statistical 


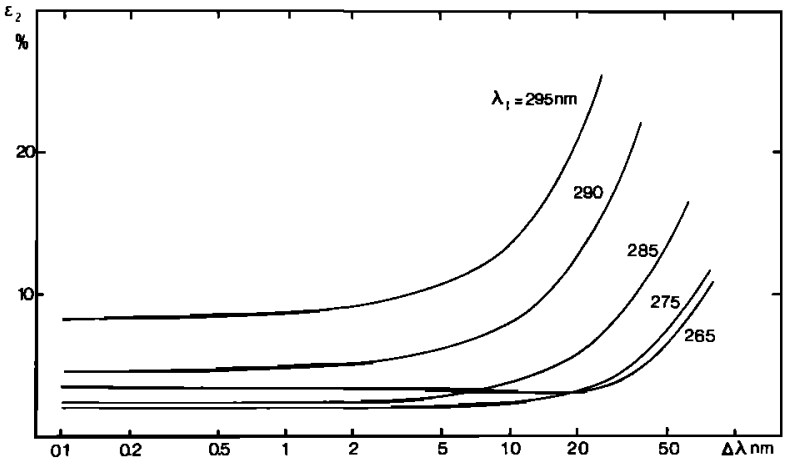

Fig. 1. Variation of the systematic error $\varepsilon_{2}$ as a function of the wavelength difference $\Delta \lambda=\lambda_{2}-\lambda_{1}$, for different values of the absorbed wavelength $\lambda_{1}$ for a range $R=1 \mathrm{~km}$ (rural aerosol model).

error $\varepsilon_{1}$ can be reduced below $10^{-2}$. By using the extinction values given by Elterman [1968], the differential molecular extinction for a wavelength interval $\Delta \lambda=\lambda_{1}-\lambda_{2}=5 \mathrm{~nm}$ can be as large as 0.1 in the wavelength range considered (270$310 \mathrm{~nm}$ ) and can thus not be neglected. A correction has to be made by measuring the ground-level pressure and temperature to derive the atmospheric density in the first kilometers. An uncertainty of a few percents in this determination will reduce the error due to molecular extinction to less than $5 \times 10^{-3}$.

The remaining error in $\varepsilon_{2}$ is then related to the aerosol extinction, and a further distinction should be made between ozone measurements performed in rural (nonpolluted) or urban areas.

Rural areas: We have calculated the variations of $\varepsilon_{2}$ as a function of wavelength and range by using aerosol particles concentration as given by Elterman [1970] and typical of rural conditions. These variations are given on Figure 1 for different values of $\lambda_{1}$ and $\Delta \lambda=\lambda_{2}-\lambda_{1}$ for a vertical range $R$ $=1 \mathrm{~km}$. The optimization of $\lambda_{1}$ and $\Delta \lambda$ in the wavelength range $265-285 \mathrm{~nm}$ leads to values of $\varepsilon_{2}$ less than $2 \%$, which can be further reduced if needed by using the experimental procedure adopted for urban or polluted areas and described in the following subsection.

Urban or polluted areas: Owing to the large aerosol particles concentrations in the boundary layer, $\varepsilon_{2}$ can reach values as large as $10^{-1}$, and a complementary measurement will be needed to eliminate the aerosol differential extinc-

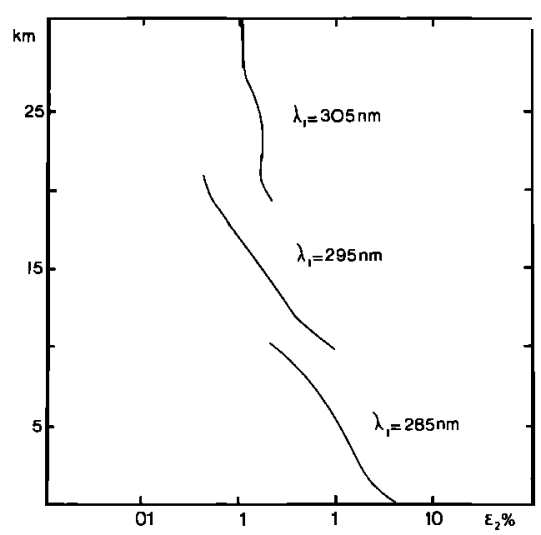

Fig. 2. Variation of the systematic error $\varepsilon_{2}$ as a function of altitude, for $\Delta \lambda=5 \mathrm{~nm}$, and the three values of $\lambda_{1}$ that optimize the statistical error $\varepsilon_{1}$ (see text).

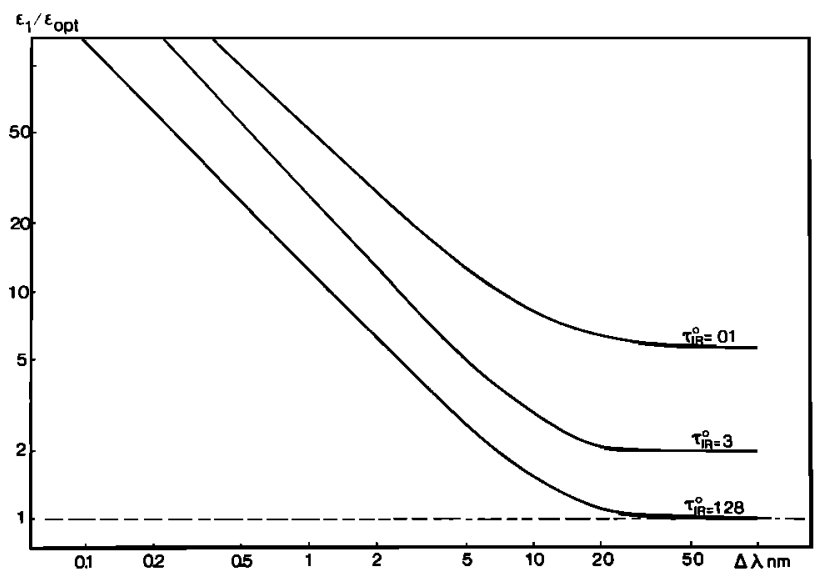

Fig. 3. Variation of the statistical error $\varepsilon_{1}$ as a function of $\Delta \lambda$ for different optical thicknesses $\tau_{1 R}{ }^{0}$ corresponding to different wavelengths $\lambda_{1}$ or ranges. $\varepsilon_{1}$ is normalized to its minimum value.

tion. This can be done, for example, by using three wavelengths in the $265-285 \mathrm{~nm}$ range with the same wavelength interval $\Delta \lambda=5 \mathrm{~nm}$. The aerosol differential extinction can then be substracted, if one assumes a linear variation for the aerosol scattering and extinction properties over $10 \mathrm{~nm}$. This will avoid the use of a theoretical model that depends on the nature and shape of the particles. Taking into account the experimental errors and the modeling uncertainties, the estimated upper limit of $\varepsilon_{2}$ will then be reduced to 2-3\%.

Upper tropospheric and stratospheric measurements: Above $2 \mathrm{~km}, \varepsilon_{2}$ decreases rapidly with altitude, as represented in Figure 2, for average values of higher tropospheric and stratospheric aerosol content. The choice of the operating wavelengths is then determined by calculating the minimum value of $\varepsilon_{1}$ as a function of the three interrelated and wavelength-dependent parameters $\tau_{1 R}{ }^{0}, \tau_{2 R}{ }^{0}, \Delta \lambda$ (see the appendix for notations and definitions). For a given value of the larger absorption wavelength $\lambda_{1}$, the minimum is obtained for $\tau_{2}^{0}=0$. This condition cannot be experimentally achieved in the case of the ozone UV absorption bands, which present continuous absorption features over a wide wavelength range. Thus the optimization procedure will consist of first calculating the value of $\tau_{1 R}{ }^{0}$ and thus $\lambda_{1}$, corresponding to the minimum value of $\varepsilon_{1}$ for $\Delta \lambda=\infty$ (i.e., $\tau_{2 R}{ }^{0}=0$ ) and then evaluating the decrease in accuracy that results of the choice of a finite value of $\Delta \lambda$ compatible with both the experimental constraints and a maximum value of

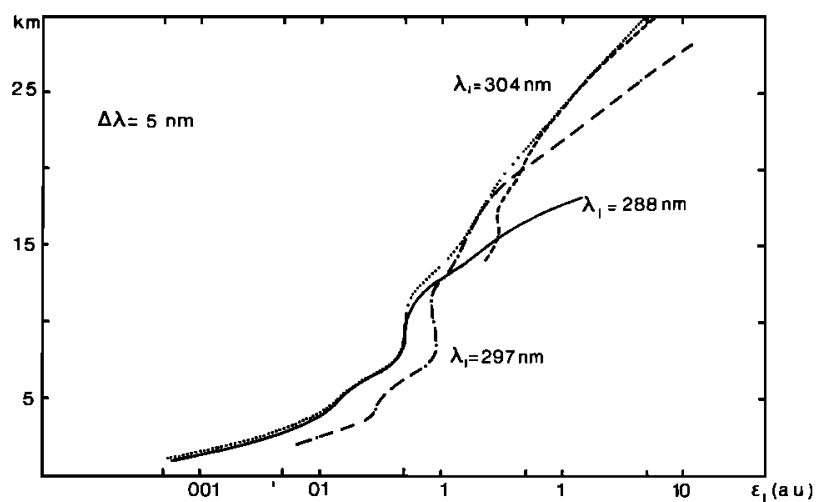

Fig. 4. Variation of the statistical error $\varepsilon_{1}$ as a function of height for three different range optimized wavelengths. The dotted curve represents the optimum value of $\varepsilon_{1}$ for each altitude. 
TABLE 1. Lidar System Characteristics

\begin{tabular}{lc}
\hline \multicolumn{1}{c}{ Emitter } & \multicolumn{1}{c}{ Receiver } \\
\hline Energy $(300 \mathrm{~nm})=40 \mathrm{~mJ}$ & $\phi$ telescope $=36 \mathrm{~cm}$ \\
Pulse duration $=12 \mathrm{~ns}$ & wide-band filter: \\
Repetition rate $=10 \mathrm{~Hz}$ & $\Delta \lambda_{\text {receever }}=70 \mathrm{~nm}$ (FWHM) \\
Emission linewidth & narrow band filters \\
$\Delta \lambda=5 \mathrm{pm}$ & $\Delta \lambda_{\text {receever }}=3 \mathrm{~nm}(\mathrm{FWHM})$ \\
Beam divergence $<0.5 \mathrm{mrd}$ & field of view $=1 \mathrm{mrd}$ \\
\hline
\end{tabular}

$\varepsilon_{2}$ as calculated above. Megie and Menzies [1980] have shown that the optimum value of $\tau_{1 R}{ }^{0}$ is 1.28 , in the case of shot-noise limited signal when one neglects the off line $\left(\lambda_{2}\right)$ absorption (for ozone measurements this corresponds to large values of $\Delta \lambda$ ). We have represented on Figure 3 the variations of $\varepsilon_{1}$ relative to its minimum value as a function of $\Delta \lambda$. The values of the atmospheric density as a function of altitude required for the calculations were taken from the U.S. Standard Atmosphere [1976]. By comparing these variations with the ones obtained for $\varepsilon_{2}$ (Figure 1), one can see that the optimum wavelength interval has to be in the range $5-15 \mathrm{~nm}$. The final choice of $5 \mathrm{~nm}$ has been adopted by considering the maximum tuning range of the laser systems and the possibility of using several wavelength pairs for the measurement within this range.

The optimum value of $\lambda_{1}$ as determined above is only valid for a given altitude range $R$. On an experimental point of view, it seems impossible to use as many wavelength pairs as the number of altitude levels of the measurement. Therefore, we have calculated the altitude variations of $\varepsilon_{1}\left(\lambda_{1}, \Delta \lambda\right)$ by using the mean ozone profile of Krueger and Minzer [1976] typical of middle latitude regions. These relative variations represented on an arbitrary scale, corresponding to experimental conditions, are given on Figure 4 for three wavelength pairs $\left(\lambda_{1}, \lambda_{2}\right)$. The shorter wavelengths are used to probe the lower altitude levels, and the useful range of a given pair can be extended up to $7-8 \mathrm{~km}$ so that the measurement accuracy stays between its optimum value $\varepsilon$ and $1.2 \varepsilon$.

As a final step, using the above mentioned atmospheric and ozone models and the operational characteristics of the lidar system described in the next section (Table 1), we have computed the optimized acquisition time $t_{\varepsilon}$ required to obtain a given accuracy $\varepsilon$ on the ozone number density (Figure 5). (To extrapolate these results to other experimental parameters, it should be noticed that $t_{\varepsilon}$ is inversely proportional to the product $\left(P_{e} A \Delta R^{3}\right)$ where $P_{e}$ is the laser average output power, $A$ the telescope area, and $\Delta R$ the range resolution.) This acquisition time increases very rapidly above the altitude of the ozone maximum $\left(z_{M}=23 \mathrm{~km}\right.$ in the reference model of Krueger and Minzer [1976]). This constitutes a limitation of the differential absorption lidar technique in the UV wavelength range as only the ozone number density profile up to altitude levels of the order of $z_{M}$ $+7 \mathrm{~km}$ can be retrieved with the presently available system within acquisition times compatible with measurements of geophysical interest.

\section{Interference With Other Absorbing Gases}

Two minor constituents have to be considered as potential interference absorbers in the $300 \mathrm{~nm}$ wavelength range.

1. The sulfur dioxide $\mathrm{SO}_{2}$ absorption spectrum presents a band structure with a spectral width for the individual features of $1 \mathrm{~nm}$ [Thompson, 1975]. The differential cross section between an absorption maximum and a minimum $(\Delta \lambda$ $\sim 1.5 \mathrm{~nm}$ ) can reach $10^{-18} \mathrm{~cm}^{2}$. In the case of large amounts of $\mathrm{SO}_{2}$ in the troposphere over urban areas, the corresponding differential absorption coefficient can reach values as large as $0.1 \mathrm{~km}^{-1}$ at the ground level [Stewart et al., 1978]. To avoid any interference, the two laser wavelengths $\lambda_{1}$ and $\lambda_{2}$ should be chosen so that the $\mathrm{SO}_{2}$ differential absorption vanishes. This choice is always possible within $0.3 \mathrm{~nm}$ of a predetermined wavelength.

2. The nitrogen dioxide $\mathrm{NO}_{2}$ presents in the same wavelength range absorption bands with cross-section values of the order of $10^{-19} \mathrm{~cm}^{2}$ [Bass et al., 1976]. The differential cross section for a $5 \mathrm{~nm}$ wavelength interval is then $2.510^{-20}$ $\mathrm{cm}^{2}$. It results, if one considers the higher mixing ratios typical of urban or polluted areas $(\sim 0.3 \mathrm{ppm}$ [Seinfeld, 1975]), in a differential absorption coefficient of $0.015 \mathrm{~km}^{-1}$ at the ground level. The corresponding error on the ozone measurement will be $2 \%$ and can be taken care of by the same procedure as for $\mathrm{SO}_{2}$.

In any case, the high altitude measurements will not be affected due to the very low atmospheric content in these interfering species above the boundary layer.

\section{Temporal Variations of the Scattering Medium}

If the two wavelengths are not simultaneously emitted, variations in the optical properties of the scattering medium might occur between the two laser shots, owing to atmospheric transport. This will be of particular importance at lower altitudes if the aerosol content is high or at the tropopause level in the presence of cirrus clouds. Thus, even if the integration time required for the measurement is large, the switching between the two wavelengths will have to be made with a time constant much smaller than the time constant characteristic of the dynamical transport. The experimental system will have to take this requirement into account (see section 3 ), and the possible design of a dual cavity laser emitting simultaneously at two wavelengths should also be investigated.

\section{Altitude Dependence of the Ozone Absorption Cross Sections}

The value of the absorption cross sections that we used to derive the ozone number densities are taken from $\operatorname{Inn}$ and

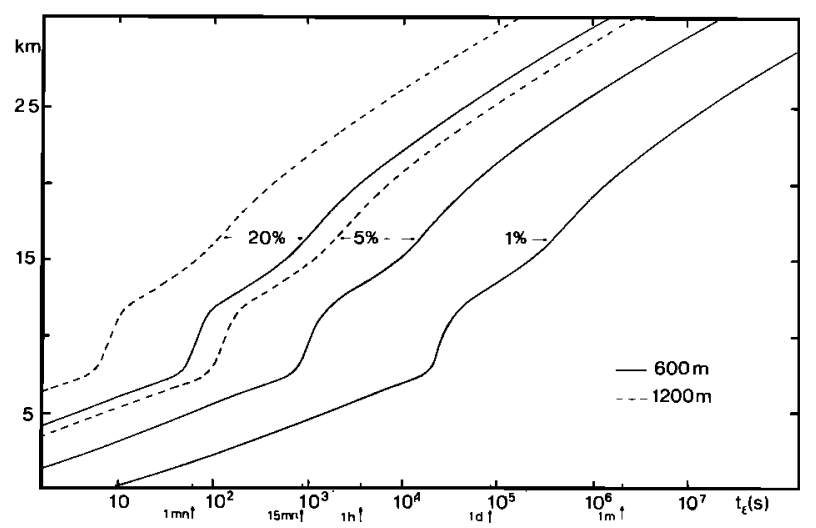

Fig. 5 Measurement acquisition time required to reach a quoted relative accuracy as a function of height, for different vertical resolutions. These curves are given for $\Delta \lambda=5 \mathrm{~nm}$ and optimized wavelengths at each altitude range (the system parameters are given in Table 1). 


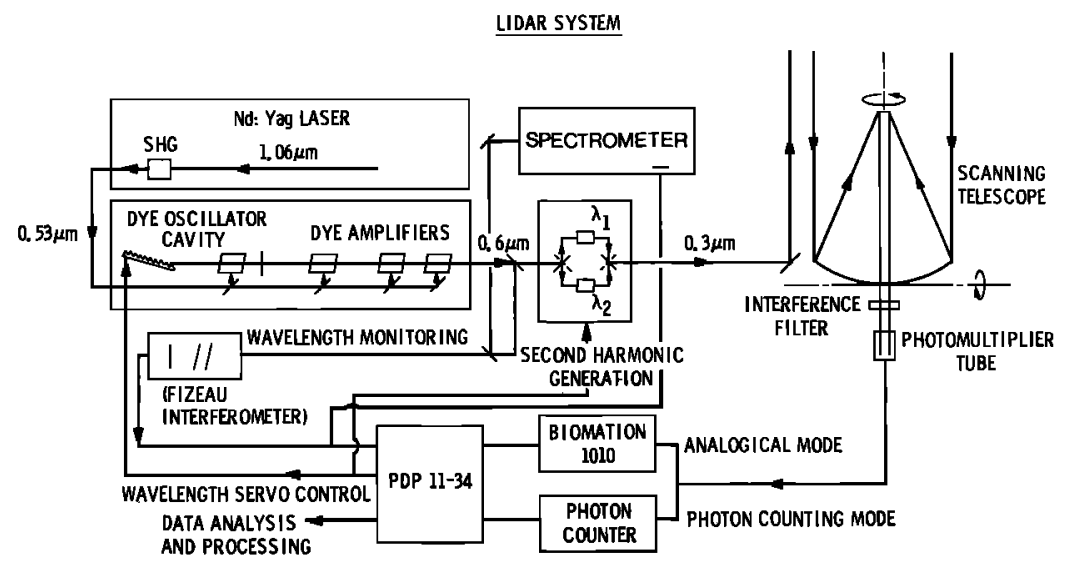

Fig. 6. Synoptic diagram of the lidar system.

Tanaka [1953]. The spectral resolution of their measurements is lower than the resolution of the lidar measurements as given by the laser linewidth $(\sim 50,000)$. The assumption has thus to be made that the mean value of the absorption cross section is the same over these different wavelength intervals. This is not experimentally confirmed, but the precise knowledge of the emitted wavelength (see the following section) will also allow us to correct our data from this systematic error if high resolution absorption spectra of ozone become available in this wavelength range.

The ozone absorption cross sections are temperature dependent mainly in the Huggins bands above $310 \mathrm{~nm}$ where variations as large as a factor of 2 can be observed for a 100 $\mathrm{K}$ temperature difference. Low resolution measurements [Vigroux, 1953] have shown that the absorption minima are more sensitive than the maxima to the temperature variations. In the Hartley bands, the relative temperature variation of the cross section is much lower: $1 \%$ for a $10 \mathrm{~K}$ variation [Vigroux, 1953]. Therefore, the use of an atmospheric model to take into account this temperature dependence of the absorption cross section and an a posteriori control using the radiosonde measurements of the nearby meteorological stations will reduce this uncertainty on the ozone profile to less than $0.5 \%$.

\section{EXPERIMENTAL SYSTEM}

The system evaluation conducted in the previous section shows that the measurement of the ozone number density profile from the ground up to $\sim 30 \mathrm{~km}$, using the DIAL technique, requires a dual wavelength lidar to minimize the interferences due to molecular and aerosol extinction. A single wavelength system might be used for the measurements between 15 and $30 \mathrm{~km}$ [Uchino et al., 1980] as long as further assumptions are made with respect to the atmospheric number density and aerosol content at these levels. As shown in section 2 , the value of the wavelengths pair used for the measurement has to be adapted to the altitude range to fulfill all the optimization criteria. Taking these requirements into account leads to the choice of a laser system tunable over a wide wavelength range from 280 to $310 \mathrm{~nm}$. At the present time, the frequency doubled dye lasers seem to be the best candidates for an operational system if one considers their actual state of development. Such systems have already been used in airborne measurements [Browell et al., 1981] and are considered as an important part of a potential spaceborne lidar $[N A S A, 1979 b]$. Also, the choice of an industrially developed $\mathrm{Nd}^{3+}$ YAG laser as a pump laser refers to their actual technical achievement. The possible use of other types of lasers, such as excimer lasers [Uchino et al., 1979], either as the pump laser or as the active laser itself using various methods for additional generation of wavelength, will have nevertheless to be considered for future developments.

A schematic diagram of the lidar system is represented on Figure 6.

\section{Transmitter}

The active part of the transmitter is a laser pumped frequency doubled dye laser. The pump laser is a $\mathrm{Nd}^{3+}$ YAG laser (Quantel model 480) emitting an energy of $750 \mathrm{~mJ}$ at $1.06 \mu \mathrm{m}$ with a repetition rate of $10 \mathrm{~Hz}$. This IR emission is frequency doubled with an efficiency of $40 \%$ resulting in an available pump energy of $300 \mathrm{~mJ}$ at $0.53 \mu \mathrm{m}$. The transversaly pumped dye laser (Jobin Yvon model HPHR) includes one oscillator cavity and three amplifier stages [Bos, 1981]. To cover the wavelength range from 570 to $620 \mathrm{~nm}$, two dye solutions are used as the active medium (1) $570-600 \mathrm{~nm}$ a $5 \times$ $10^{-4} \mathrm{M} / 1$ solution of $\mathrm{Rh} 6 \mathrm{G}$ in water $+5 \%$ ammonix; (2) 590 $620 \mathrm{~nm}$ a $5 \times 10^{-4} \mathrm{M} / 1$ solution of $\mathrm{Rh} 610$ in water $+5 \%$ ammonix.

The energy conversion efficiency is $40 \%$ corresponding to an output energy of $120 \mathrm{~mJ}$. The wavelength selection and spectral narrowing of the emitted laser line are made by using a 2750 groves $\mathrm{mm}^{-1}$ grating at Littrow incidence. The emission characteristics of the laser are summarized in the Table 1.

To adapt these characteristics to the requirements brought out from section 2, two experimental achievements remain to be made.

1. The output wavelength has to be converted to a value in the near UV wavelength range by second harmonic generation using a KDP crystal. Owing to the high peak power of the fundamental emission (20 MW) the energy conversion efficiency is close to $35 \%$. The output energy between 285 and $310 \mathrm{~nm}$ is equal to $40 \mathrm{~mJ}$.

2. The laser system has to emit sequentially two wavelengths. It is designed so that the full sequence of wavelength switching is automatic. The output wavelength of the dye laser fundamental emission is monitored by using a spectrometer and a Fizeau interferometer, giving patterns recorded on diode arrays. A computer-controlled servo mechanism [Cahen et al., 1981b] is used to both ensure the 


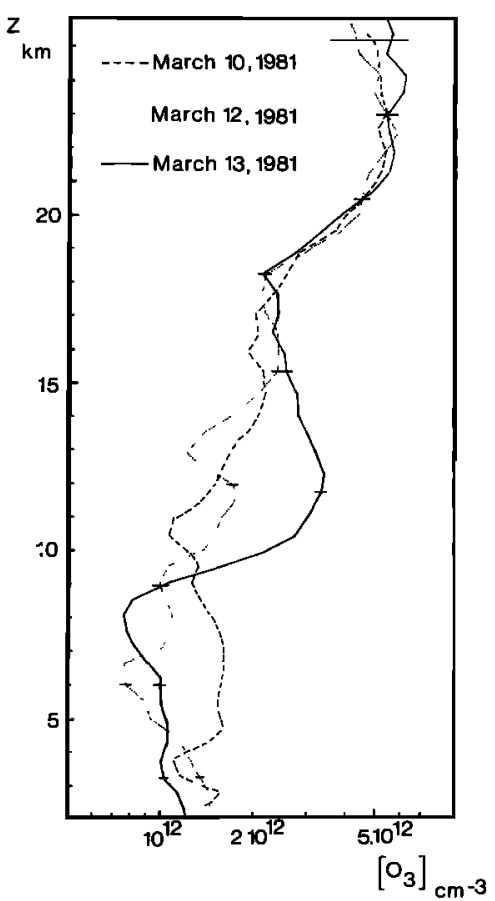

Fig. 7. Vertical ozone concentration profiles as obtained by lidar soundings. March 10 and 13 are representative of particular meteorological conditions (see text).

stability of the output wavelength at a value $\lambda_{1}$ and to switch automatically the emission wavelength from $\lambda_{1}$ to a second preprogramed value $\lambda_{2}$. To allow this switching to be fast ( $t$ $<1$ s) and to avoid the experimental difficulties connected to the accuracy of the doubling crystals positioning as a function of wavelength, two KDP crystals are used that are preset to the optimum value of the phase matching angle for $\lambda_{1}$ and $\lambda_{2}$. The laser beam is then mechanically switched from one crystal to the other, depending on the incident wavelength. When a second wavelengths pair has to be used, the values of $\lambda_{1}$ and $\lambda_{2}$ as programed for the servocontrol loop are changed so as the crystal angles. By using this system, the stability of the laser emission wavelength is better than $1 \mathrm{pm}$ and the switching operation takes place in less than $0.5 \mathrm{~s}$.

As the laser divergence is smaller than $5 \times 10^{-4} \mathrm{rad}$, no transmitting optics is used and the beam is sent directly upward by using a total reflection prism.

\section{Optical Receiver}

The backscattered signal is collected by a $36 \mathrm{~cm}$ scanning telescope in a Cassegrain configuration. The equivalent focal length of the two mirrors combination is $3 \mathrm{~m}$. The distance between the emitting point and the telescope axis can be varied, depending on the altitude range of the observations to increase or decrease the range at which the fields of view of the transmitter and the receiver begin to overlap. This will avoid saturation of the photomultiplier tube from the low altitude backscattered signals.

The telescope field of view is adjusted by using a remotely controlled iris and can thus be reduced to its limit value compatible with the laser divergence. The spectral bandwith of the receiver can be reduced by either using a wide band interference filter $(70 \mathrm{~nm})$ or several narrow bandwiths interference filters $(3 \mathrm{~nm})$ which can be automatically changed when the laser emission wavelengths are changed. The signal is detected by using a Hamamatsu R $212 \mathrm{UH}$ photomultiplier tube.

\section{Electronic Processing and Data Acquisition}

The dynamical range of the backscattered signal between the ground and $30 \mathrm{~km}$ can be as large as $10^{6}$ according to equation (1) in the appendix. We thus use two acquisition modes. (1) For the lower altitude range the electrical signal delivered by the PMT is analysed by using a transient waveform recorder (Biomation 1010) with a sampling frequency of $10 \mathrm{MHz}$, which corresponds to a maximum altitude resolution of $15 \mathrm{~m}$. A 10-bit converter is used for the analog to digital conversion. (2) For the altitude levels above $10-12 \mathrm{~km}$, a 256 channels photon counter is used in parallel with the transient recorder, so that the two acquisition modes overlap with respect to the altitude range. The timegate of the photon counter can be varied from 1 to $8 \mu \mathrm{s}$, and the maximum altitude resolution is thus $150 \mathrm{~m}$.

The data provided by the two acquisition systems are then fed into a PDP 11-34 computer and are stored on a floppy disk. A presummation of the single laser shot signals is made to reduce the volume of stored data.

\section{Automatization of the Observations}

The PDP 11-34 computer is used to control the full sequence of a DIAL measurement. The experimental parameters (acquisition time, altitude resolution, values of the various laser wavelengths, switching time, etc.) are typed in to start automatically the sequence of laser firings. During the experiment, the laser energy and emission wavelength are continuously monitored, and the data acquisition takes place only if all these parameters are within the range of predetermined values.

The reliability of this operational scheme and its potentiality for routine measurements have been successfully tested during several field measurements campaigns in 1980-1981.

\section{Data Analysis}

As shown by equation (3) in the appendix, the ozone number density is given by the difference between the range derivatives of the local optical thicknesses at the two wavelengths $\lambda_{1}$ and $\lambda_{2}$. The values of these derivatives are deduced from the slope of the backscattered signal as a function of range.

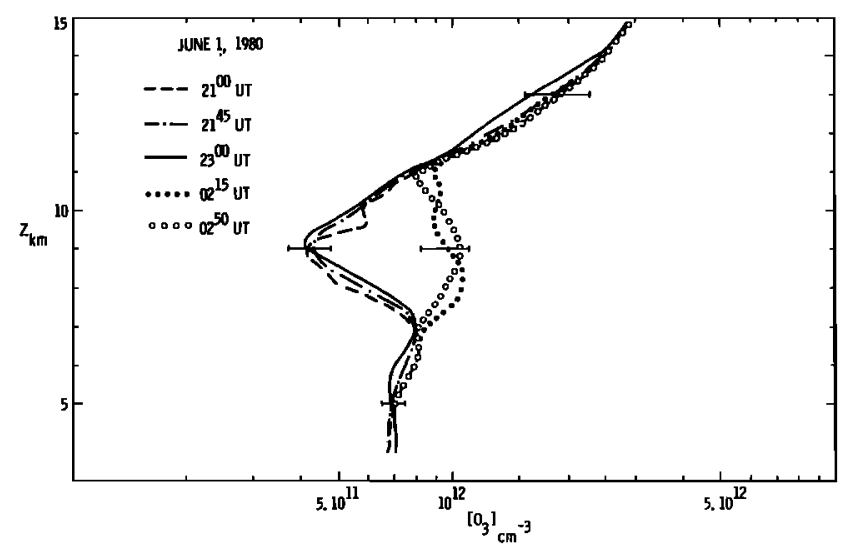

Fig. 8. Short-term variability of ozone concentration profiles as recorded during the night of June 1-2. 


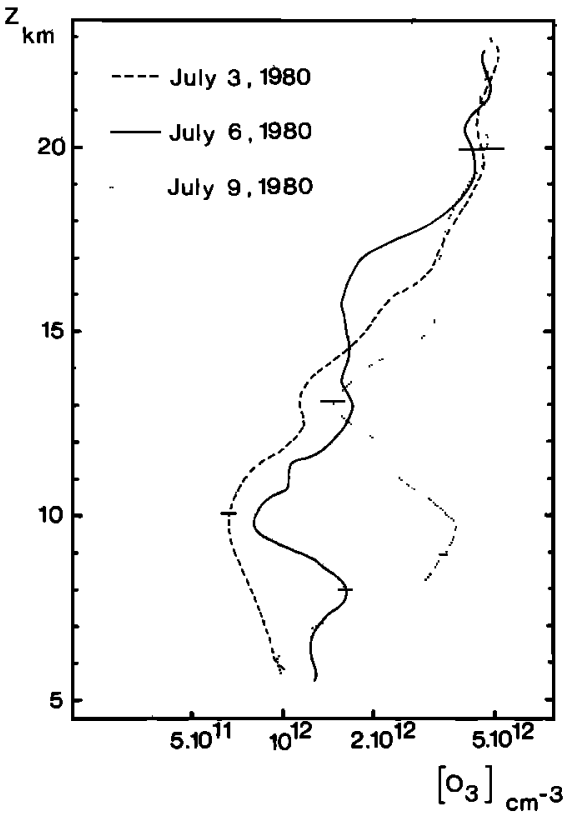

Fig. 9. Ozone concentration profiles recorded during July 1980 and showing evidence for an ozone bulge occurence on July 9 .

For each wavelength $\lambda_{i}$, the signal is sampled with respect to time (i.e., range) at a rate that depends on the acquisition mode used (see section 2). The value $S_{i j}$ of the signal in each channel $j$ is stored. The background level $B$ and the background noise $N_{B}$ are evaluated by using the higher altitude channels where no backscattered signal is detected. The range correction $\left(R_{j}\right)$ is made to compute the quantities $L_{i j}=$ $\ln \left\{R_{j}^{2} \times\left(S_{i j}-B\right)\right\}$, which depend on the total integrated thickness $\tau_{i}$. To calculate the derivative

$$
D_{i j}=\left(\frac{d L_{i j}}{d R}\right)_{R=R j}
$$

the signal corresponding to the $2 n+1$ channels $(j-n, j+n)$ is fitted to a second-order polynomial function $a_{y j} R^{2}+b_{y} R$ $+c_{i j}$ by using a least mean square method. From the values of $a_{i j}$ and $b_{i j}$, the corresponding value of $D_{i j}$ is determined. The value of $n$ is chosen so that the difference between experimental and fitted values is less than twice the standard deviation, and the range interval that corresponds to $2 n+1$ channels is less than $1200 \mathrm{~m}$. The ultimate vertical resolution $\Delta R$ is chosen to compute the average value $\overline{D_{i}}(R)$

$$
\overline{D_{i}}(R)=\frac{1}{\Delta R} \int_{\Delta R} D_{i j} d R,
$$

The average ozone number density in the range $R-\Delta R / 2$, $R+\Delta R / 2$ is then given by

$$
n_{0}(R)=\frac{\overline{D_{1}(R)}-\overline{D_{2}(R)}}{2\left(\sigma_{1}-\sigma_{2}\right)}
$$

As mentioned in section 3, two corrections are made to take into account the temperature dependence of the ozone absorption cross sections and the differential Rayleigh extinction below $5 \mathrm{~km}$, resulting in an overall uncertainty of less than $1 \%$. The statistical error on the ozone number density is determined from the calculation of the standard deviations of the $S_{i j}$ for each laser shot and each altitude range.

\section{EXPERIMENTAL ResUlTS AND Discussion}

The lidar system described in section 3 has been in operation since March 1980 at the French lidar facility for atmospheric studies located at the Haute Provence Observatory $\left(44^{\circ} \mathrm{N}, 5^{\circ} \mathrm{E}\right)$. Several field experiments have been conducted and correspond to 40 nights of observation spread throughout the year.

\section{Experimental Measurements}

Typical ozone concentration profiles as measured by the differential absorption laser method are represented in Figure 7. The main characteristics of these observations that represent the first lidar measurements of the ozone vertical profile simultaneously in the troposphere and lower stratosphere are as follows:

1. Vertical profiles are measured from the ground up to 26 $\mathbf{k m}$ for clear sky conditions.

2. Three profiles corresponding to the altitude ranges-0$8 \mathrm{~km}, 7-17 \mathrm{~km}, 15-26 \mathrm{~km}$-are obtained within $15 \mathrm{~min}$. This seyuential experimental procedure results from the wavelength optimization criteria derived in section 2 .

3. The relative accuracy corresponding to a $1 \sigma$ standard deviation on the ozone number denisity for the individual profiles-15 min integration time-and taking into account the error analysis of section 2 is (1) better than $5 \%$ at the tropospheric altitude levels for a vertical resolution of $450 \mathrm{~m}$ (however, in the presence of cirrus clouds at the tropopause level (less than $500 \mathrm{~m}$ vertical extension as detected from lidar returns), the systematic error $\varepsilon_{2}$ can be greatly enhanced due to the rapid time evolution of the scattering medium; the lack of a simultaneous emission of the two laser wavelengths does not allow at the present time an accurate determination of the ozone number density at the cloud altitude, and the results presented hereafter are obtained only for clear sky conditions), and (2) minimum in the 20-26 $\mathrm{km}$ altitude range where it decreases down to $20 \%$ at the maximum altitude level for a vertical resolution of $1.2 \mathrm{~km}$. In this altitude range, however, the systematic errors are negligible and the ozone concentration variability is small so that further integration of the measurement can be performed to increase the accuracy to less than $10 \%$ for a $1-$ to 2-hour integration time.

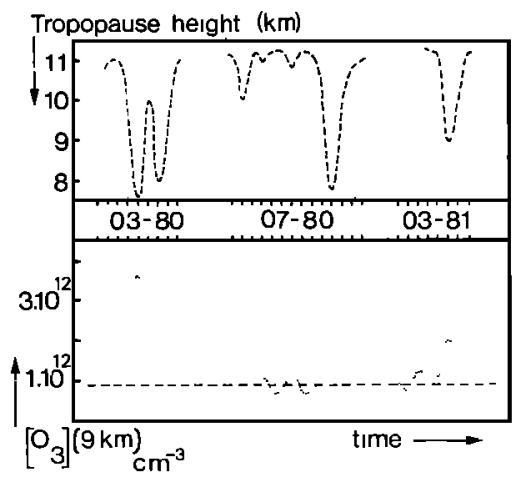

Fig. 10. Correlated variations of the ozone concentration at 9 $\mathrm{km}$ as measured by lidar soundings and of the tropopause height as obtained from radiosoundings at the nearby meteorological station at Nîmes. (For the March 80 observations, the weather conditions only allowed a 3-day lidar measurement period.) The dashed line corresponds to the average ozone concentration given by Krueger and Minzer [1976] at $9 \mathrm{~km}$. 
These experimentally obtained characteristics are very close to the values expected from the error analysis of section 2 (Figure 5). Furthermore, comparisons between ozone measurements by lidar soundings and other conventional techniques, have been performed during the international ozone campaign held in the south of France in June 1981, [Upper Atmospheric Bulletin, 1981]. The results, which show good agreement between lidar and balloonborne ozonosondes, are to be published as part of a global data set in the near future.

\section{Short-Term Variability of the Ozone Number Density}

The statistical analysis of the measured ozone profiles shows the existence of large variations in the ozone number density below $16 \mathrm{~km}$ even within short observation times, whereas in the upper altitude levels, above $20 \mathrm{~km}$, the observed variations remain within the experimental error bars $(20 \%)$. As an example of this short-term variability, successive profiles recorded during the night of June 1, 1980, are represented on Figure 8. A two-fold increase in the ozone number density at $10 \mathrm{~km}$ has occurred between 9 PM and 2:30 AM on the following day. The careful analysis of the data on each laser wavelength does not give evidence for the presence of cirrus clouds at this altitude, which might have introduced a systematic error in the derived ozone concentration. The altitude of the tropopause as determined from the radiosonde data (launching time 2:00 AM) of the nearby meteorological station of Nîmes $\left(43.5^{\circ} \mathrm{N}, 4.2^{\circ} \mathrm{E}\right)$ was $12 \mathrm{~km}$ on this typical day and corresponds to the minimum observed in the ozone density in this altitude range at the end of the night. Such ozone variations, already observed with other experimental techniques [Dütsch, 1979] and related to the horizontal transport at the tropopause level with short characteristic scales of the order of $100 \mathrm{~km}$ seem to be a common feature. The corresponding variations of the ozone total content remain below $1 \%$ and will not thus be detected by the usual UV or IR ground-based spectroscopic techniques. It is, however, important to point out that the shape of the vertical ozone profile is modified and the presence of such structures may lead to incertainties in the inversion procedure used for the determination of ozone profile from integrated satellite-borne or ground-based measurements.

\section{Day to Day Variations}

Large variations in the ozone number density are also observed on a day-to-day basis. They are related to larger scale horizontal transport as compared with the short-term variations previously analysed. As an example, the vertical ozone profile recorded during the night of July 9, 1980 (Figure 9) shows the presence of a very large ozone bulge with concentration up to $3 \times 10^{12} \mathrm{~cm}^{-3}$ at the $10-\mathrm{km}$ altitude level. For comparison, the average profiles observed during the beginning of July 1980 are plotted on the same figure. Such increases of the ozone concentration at the tropopause level have been observed on several occasions during our field experiments (Figure 7). The altitude of the ozone bulge may vary from 10 to $12 \mathrm{~km}$ down to 6 to $8 \mathrm{~km}$ as on March 11,1981 ; in this latter case the peak concentration decreases when the bulge is observed at lower altitudes.

From the meteorological network data, one can show that these increases are systematically correlated with a $2-3 \mathrm{~km}$ decrease of the tropopause height (Figure 10) corresponding thus to the presence of warmer air at these levels over southern France. A detailed analysis of one of these situations (July 1980) has already been performed by using the meteorological charts at various altitude levels in the troposphere and lower stratosphere [Pelon et al., 1981]. A meridional circulation was established at the 300 mbar pressure level due to the presence of a low pressure center over northern Europe. Such cyclonic-anticyclonic situations as encountered on July 9, 1980, over Europe seem to be a typical feature of ozone intrusions [Danielsen, 1980]. It was always observed during large ozone increases at the higher levels or before such episodes when they were detected at lower altitudes. This circulation brought stratospheric air of polar origin into the lower latitude troposphere where it kept its general characteristics such as the higher temperature and higher ozone content usually observed $3-5 \mathrm{~km}$ above the polar tropopause. The altitude variations observed for the ozone concentration increase is related to the time elapsed between the intrusion and the lidar observation and thus to the location of the stratosphere-troposphere mass exchange. A lower altitude increase corresponds to a longer residence time in the troposphere, which could explain the larger altitude extent due to diffusion processes at tropospheric altitudes.

The variations of the ozone total vertical content corresponding to such events as compared with its mean value can be larger than 10-15\%. From the analysis of air masses trajectories on the days preceding and following the July 1980 event, the horizontal extent of the injected stratospheric air mass is of the order of 1500 by $500 \mathrm{~km}$, which corresponds to $0.3 \%$ of the total area of the northern hemisphere and to a total number of ozone molecules of 7.5 $\times 10^{33}$. This number could be compared with the $1.7 \times 10^{29}$ molecule $\mathrm{s}^{-1}$ or $5.4 \times 10^{36}$ molecule per year given by [Fabian et al., 1977] as an estimate of the total annual stratosphere-troposphere mass exchange for the northern hemisphere.

\section{Lower Troposphere Ozone Profile}

As already pointed out, ozone monitoring in the troposphere $(0-15 \mathrm{~km})$ has been performed for the first time by using a ground-based remote sensing technique. The relative accuracy on the ozone number density profile is better than $5 \%$ for a $15 \mathrm{~min}$ integration time and a vertical resolution of $450 \mathrm{~m}$. As compared with point measurements at ground level, the lidar technique will bring scientific improvements to such studies as (1) the relative importance of the various ozone sources in the troposphere (photochemical formation, horizontal or vertical transport) by continuously monitoring the ozone altitude profile to identify the origin of the observed variations and (2) the study of the transport and removal processes of ozone in polluted areas to determine its tropospheric residence time as it is transported downwind from source rich areas and to evaluate the influence of local sources in terms of global ozone budget.

These first data obtained at the Haute Provence Observatory, which can be considered as representative of pollution free areas, show that in most cases ozone is rather well mixed in the troposphere up to $8 \mathrm{~km}$. The increase in mixing ratio usually observed above $8 \mathrm{~km}$ is thus related to a high altitude source either stratospheric as shown above or in the high troposphere as suggested by various authors [Kley et $a l ., 1981]$. More systematic observations are now required to analyze further these two possibilities. 


\section{Conclusions}

Lidar monitoring of the vertical ozone profile in the troposphere and lower stratosphere has been performed on an operational basis during the years 1980-1981 at the French lidar facility set up at the Haute Provence Observatory. These measurements demonstrate the potentiality of the differential absorption lidar technique for the study of the ozone variability in the dynamical region in terms of troposphere-stratosphere exchange and total ozone budget. The accuracy, height resolution, and integration time presently obtained are already sufficient to fulfill these main geophysical objectives. The extension of the measurements to the daytime will allow a continuous monitoring during a full diurnal cycle. The implementation of a ground-based network and the development of a space-borne lidar (either airplane or satellite), as it is now undertaken by various space agencies, should be considered in view of these first results as an important contribution to the global monitoring of the ozone layer in the next decade.

\section{ApPENdix: ERror Calculations}

The usual lidar equation is written as

$$
N_{\lambda R}=N_{e \lambda} \cdot \beta_{\lambda} \cdot \Delta R \cdot \frac{A}{R^{2}} \cdot \eta \cdot \eta^{\prime} \cdot \exp \left\{-2\left(\tau_{\lambda R}{ }^{0}+\tau_{\lambda R}{ }^{e}\right)\right\}
$$

where $N_{\lambda R}$ is the number of backscattered photoelectrons at wavelength $\lambda$ from the cell at the range $R$ and of thickness $\Delta R ; N_{e \lambda}$, number of emitted photons in the laser pulse at wavelength $\lambda ; \beta_{\lambda R}$, atmospheric backscattering coefficient at wavelength $\lambda$ and range $R ; \Delta R$, thickness of the range cell corresponding to a time gate interval of $2 \Delta R / c$, where $c$ is the velocity of light; $A$, receiver area; $\eta$, detector efficiency; $\eta^{\prime}$, optical efficiency of the transmitter receiver system; $\tau_{\lambda R}{ }^{0}$, integrated optical thickness due to the absorption by the constituent under study, i.e., ozone:

$$
\tau_{\lambda R}{ }^{0}=\int_{0}^{R} \sigma_{\lambda R} n_{0}(R) d R
$$

where $\sigma_{\lambda R}$ is the ozone absorption cross section and $n_{0}(R)$ the ozone number density; $\tau_{\lambda R}{ }^{e}$, integrated optical thickness excluding the ozone absorption; $\tau_{\lambda R}$, total integrated optical thickness $\tau_{\lambda R}=\tau_{\lambda R}{ }^{0}+\tau_{\lambda R}{ }^{e}$.

The local optical thickness $\Delta \tau_{\lambda R}=\tau_{\lambda R+\Delta R}-\tau_{\lambda R}$ within the range cell $R, R+\Delta R$ is obtained by processing four different laser signals at two different wavelengths $\lambda_{1}$ and $\lambda_{2}$ and from two successive cells at ranges $R_{1}$ and $R_{2}=R_{1}+\Delta R$

$$
2\left(\Delta \tau_{1 R}-\Delta \tau_{2 R}\right)=\ln \frac{N_{22} N_{11}}{N_{12} N_{21}}+\ln \frac{\beta_{12} \beta_{21}}{\beta_{22} \beta_{11}}
$$

where the first subscript refers to the wavelength and the second one, if present, to the range.

The signal to noise ratio $S_{\lambda R}$ for a single wavelength measurement is given, in the case of an incoherent detection scheme and assuming that the fluctuations of the various sources of the photodetector current are governed by Poisson statistics by

$$
S_{\lambda R}=\frac{N_{\lambda R}}{\left(N_{\lambda R}+N_{B}+N_{D}\right)^{1 / 2}}
$$

where $N_{B}$ is the number of background photons and $N_{D}$ the square of the photodetector dark current fluctuations within the time gate interval $2 \Delta R / c$.

In the usual derivation of the DIAL method, one considers that the wavelength variations of $\beta_{\lambda R}$ and $\tau_{\lambda R}{ }^{e}$ between $\lambda_{1}$ and $\lambda_{2}$ contribute only to the systematic error term $\varepsilon_{2}$ (see below) [see, for example, Schotland, 1974] so that (3) can be rewritten as

$$
\Delta \tau_{1 R}^{\circ}-\Delta \tau_{2 R}^{\circ}=\frac{1}{2} \ln \left(\frac{N_{22} N_{11}}{N_{12} N_{21}}\right)
$$

The average ozone number density $n_{0}(R)$ within the range cell $R, R+\Delta R$ is given by

$$
n_{0}(R)=\frac{\Delta \tau_{1 R}{ }^{0}-\Delta \tau_{2 R}{ }^{0}}{\left(\sigma_{1}-\sigma_{2}\right) \Delta R}
$$

The relative uncertainty $\varepsilon=\delta n_{0} / n_{0}$ is then expressed as the sum of two terms $\varepsilon_{1}+\varepsilon_{2}$ :

1. $\varepsilon_{1}$ is related to the signal uncertainty by

$$
\varepsilon_{1}=\frac{K}{2 \tau_{R}^{0} \vee N_{0}}\left(f_{1}^{2}+f_{2}^{2}\right)^{1 / 2}
$$

where

$$
K=\frac{\tau_{R}^{0}}{\Delta \tau_{R}{ }^{0}}=\frac{\int_{0}^{R} n_{0}(R) d R}{n_{0}(R) \Delta R}
$$

is wavelength independent as far as one considers that the ozone absorption cross sections are altitude independent. One can also notice that the product $K \Delta R$ does not depend on the range resolution of the lidar system (1) $\tau_{R}{ }^{0}$ is the differential integrated optical thickness: $\tau_{R}^{0}=\tau_{1 R}{ }^{0}-\tau_{2 R}{ }^{0}$; (2) $N_{0}=A \Delta R \eta \eta^{\prime} / R^{2}$ is the wavelength independent part of $N_{\lambda R}$; (3) $f_{\lambda}$ is a wavelength dependent function given by

$$
\begin{aligned}
& f_{\lambda}^{2}=\frac{e^{2 \tau_{\lambda 1}}}{\beta_{\lambda} N_{e \lambda} P_{\lambda} e^{-2 \pi_{\Lambda}{ }^{e}}}\left\{\left(1+e^{2 \mu_{\lambda}} e^{2\left(\tau_{\left.\lambda 1+\lambda^{0} / K\right)}\right)}\right.\right. \\
& +X_{\lambda}{ }^{0}\left(1+e^{4 \mu_{\lambda 1+\lambda}} e^{4\left(\tau_{\left.\lambda 1+\lambda^{0} / K\right)}\right)}\right\} \\
& \mu_{\lambda}=\ln \left\{\left(1+\frac{\Delta R}{R}\right)\left(\frac{\beta_{\lambda 1}}{\beta_{\lambda 2}}\right)^{1 / 2}\right\}+\Delta \tau_{\lambda}{ }^{e} \\
& X_{\lambda}{ }^{0}=\frac{N_{B}+N_{D}}{N_{\lambda 1}} e^{-2 \lambda^{0}}
\end{aligned}
$$

is independent of the ozone absorption; and (4) $P_{\lambda}$ is the number of laser pulses emitted at the wavelength $\lambda$.

2. $\varepsilon_{2}$ is a systematic error due to the wavelength dependence of the scattering and absorbing (other than ozone) properties of the atmospheric medium which has been neglected in the derivation of equation (5). A general expression of $\varepsilon_{2}$ has been given by Megie and Menzies [1980] as

$$
\varepsilon_{2}=\frac{K \Delta R}{\tau_{R}{ }^{0}} \cdot G(R, \lambda) \cdot \frac{\Delta \lambda}{\lambda_{1}}
$$

$G(R, \lambda)$ is a function of range and wavelength depending on the scattering and extinction properties of the atmospheric gas and particles, written as

$$
G(R, \lambda)=2\left(1-\frac{m}{4}\right) \frac{1-r_{\lambda R}}{\left(r_{\lambda R}\right)^{2}}\left(\frac{1}{h}-\frac{1}{H}\right)+m \alpha_{\rho}+4 \alpha_{M}
$$


where $r_{\lambda R}=1+\beta_{\rho} / \beta_{M}$ is the scattering ratio at wavelength $\lambda ; \beta_{\rho}, \alpha_{\rho}$ are the aerosol particles backscattering and extinction coefficients; $\beta_{M}, \alpha_{M}$ are the molecular backscattering and extinction coefficients; $m$ is the power law factor that gives the wavelength dependence of the aerosol scattering coefficients, and it depends on the nature and shape of the aerosol particles; and $H, h$ are the atmospheric and aerosol particles scale heights, respectively.

Acknowledgments. This work has been supported under contract 79-71020 from the Délégation Générale de la Recherche Scientifique et Technique. The development of the O.H.P. Lidar facility is supported by the Centre National de la Recherche Scientifique and the Institut National d'Astronomie et de Géophysique. The authors wish to acknowledge the hospitality of $\mathrm{C}$. Fehrenbach, Director of the Observatoire de Haute Provence. They are grateful to their colleagues of the lidar team of Service d'Aéronomie for their contribution to the data collection and discussion.

\section{REFERENCES}

Asai, K., T. Itabe, and T. Igarashi, Range-resolved measurements of atmospheric ozone using a differential-absorption $\mathrm{CO}_{2}$ laser radar, Appl. Phys. Lett., 35, 60, 1979.

Bass, A. M., A. E. Ledford, and A. H. Laufer, Extinction coefficients of $\mathrm{NO}_{2}$ and $\mathrm{N}_{2} \mathrm{O}_{4}, J$. Res. NBS, 80A, 143, 1976.

Bos, F., Versatile high-power single-longitudinal-mode pulsed dye laser, Appl. Opt., 20, 1886, 1981.

Browell, E. V., A. F. Carter, and S. T. Shipley, An airborne lidar system for ozone and aerosol profiling in the troposphere and lower stratosphere, in Proceedings of the Quadrennial International Ozone Symposium, edited by J. London, p. 99, NCAR (IAMAP), Boulder, Colo., 1980.

Bufton, J. L., R. W. Stewart, and Chi Weng, Remote measurement of tropospheric ozone, Appl. Opt., 18, 3363, 1979.

Byer, R. L., and M. Garbuny, Pollution detection by absorption using Mie scattering and topographic targets as retroreflectors, Appl. Opt., 12, 1496, 1973.

Cahen, C., J. Pelon, P. Flamant, and G. Megie, Mesure de la vapeur d'eau troposphérique par absorption différentielle laser, $C . R$. Acad. Sci. Paris, 292, 29, 1981 a.

Cahen, C., J. P. Jegou, J. Pelon, P. Gildwarg, and J. Porteneuve, Wavelength stabilization and control of the emission of pulsed dye lasers by means of a multibeam Fizeau interferometer, Rev. Phys. Appl., 16, 353, $1981 b$.

Danielsen, E. F., Stratospheric source for unexpectedly large values of ozone measured over the Pacific Ocean during GAMETAG, August 1977, J. Geophys. Res., 85, 401, 1980.

Dütsch, H. U., Vertical Ozone distribution and tropospheric ozone, in Proceedings of the NATO Advanced Study Institute on Atmospheric Ozone, edited by M. Nicolet and A. C. Aikin, U.S. Department of Transportation, Washington, D.C., 1979.

Elterman, L., UV, visible and IR attenuation to $50 \mathrm{~km}, R e p$. AFCRL 68-1053, Cambridge Res. Lab., U.S. Air Force, Bedford, Mass., 1968.

Elterman, L., Relationships between vertical attenuation and surface meteorological range, Appl. Opt., 9, 1804, 1970.

Fabian, P., and P. G. Pruchniewicz, Meridional distribution of ozone in the troposphere and its seasonal variations, $J$. Geophys. Res., 82, 2063, 1977.

Fredriksson, K., B. Galle, K. Nystrom, and S. Svanberg, Lidar system applied in atmospheric pollution monitoring, Appl. Opt., 18, 2998, 1979.

Inn, E. C. Y., and Y. Tanaka, Absorption coefficient of ozone in the ultraviolet and visible regions J. Opt. Soc. Am., 43, 870, 1953.

Kley, D., J. W. Drummond, M. McFarland, and S. C. Liu, Tropospheric profiles of $\mathrm{NO}_{x}, J$. Geophys. Res., 86, 3153, 1981.

Krueger, A. J., and R. A. Minzer, A mid-latitude ozone model for the 1976 U.S. standard atmosphere, J. Geophys. Res., 81, 4477, 1976.

Megie, G., J. Y. Allain, M. L. Chanin, and J. E. Blamont, Vertical profile of stratospheric ozone by lidar sounding from the ground, Nature, 270, 329, 1977.

Megie, G., and R. T. Menzies, Complementarity of UV and IR differential absorption lidar for global measurements of atmospheric species, Appl. Opt., 19, 1173, 1980.

Murray, E. R., Remote measurement of gases using discretely tunable infrared lasers, Opt. Eng., 16, 284, 1977.

NASA, The Stratosphere: Present and Future, Ref. Publ. 1049, $1979 a$.

NASA, Shuttle Atmospheric Lidar Research Program, Doc. SP$433,1979 b$.

Pelon, J., P. Flamant, M. L. Chanin, and G. Megie, Intrusion d'ozone d'origine polaire aux latitudes moyennes: Mise en évidence par sondage laser, $C . R$. Acad. Sci. Paris, 292, 319, 1981.

Remsberg, E. E., and L. L. Gordley, Analysis of differential absorption lidar from the Space Shuttle, Appl. Opt., 17, 624, 1978.

Schotland, R. M., The determination of the vertical profile of atmospheric gases by means of a ground-based optical radar, in Proceedings of the Third Symposium on Remote Sensing of Environment, University of Michigan, Ann Arbor, 1964.

Schotland, R. M., Errors in the lidar measurement of atmospheric gases by differential absorption, J. Appl. Meteorol., 13, 71, 1974.

Seinfeld, J. H., Air Pollution-Physical and Chemical Fundamentals, McGraw-Hill, New York, 1975.

Stewart, R. D., S. Hameed, and J. Pinto, The natural and perturbed troposphere, IEEE Trans. Geosci. Electron., GE-I6, 30, 1978.

Thompson, R. T., J. M. Hoell, and W. R. Wade, Measurements of $\mathrm{SO}_{2}$ absorption coefficients using a tunable dye laser, J. Appl. Phys., 46, 3040, 1975.

Uchino, O., M. Maeda, and M. Hirono, Applications of excimer lasers to laser-radar observations of the upper atmosphere, IEEE J. Quant. Elec., QE-15, 1094, 1979.

Uchino, O., M. Maeda, T. Shibata, M. Hirono, and M. Fujiwara, Measurement of stratospheric vertical ozone distribution with a $\mathrm{XeCl}$ lidar: Estimated influence of aerosols, Appl. Opt., 19, 4175, 1980.

Upper Atmospheric Programs Bulletin, 81-2, 5, 1981.

U.S. Standard Atmosphere 1976, NOAA, NASA, Washington D. C., 1976.

Vigroux, E., Contribution expérimentale à l'absorption de l'ozone, Ann. Phys. Paris, 8, 709, 1953.

(Received September 1, 1981; revised December 28, 1981; accepted January 7,1982 .) 